\title{
Territórios, populações tradicionais e conflito: a realidade da Reserva Extrativista Extremo Norte do Tocantins, Brasil
}

Territories, traditional populations and conflict: the reality of the Extrative Reserve of the Extremo Norte of Tocantins, Brazil

\author{
THAIIS HELENA TEIXEIRA \\ Universidade Federal de Viçosa \\ ID ORCID: http://orcid.org/0000-0003-3056-3309 \\ thaishel.efa@hotmail.com \\ DIEGO CAMELO MOREIRA \\ Universidade Federal de Santa Maria \\ ID ORCID: http://orcid.org/0000-0001-5368-8441 \\ diegocamelo@ymail.com \\ NATHÁLIA THAÍS COSMO DA SILVA \\ Universidade Federal de Viçosa \\ ID ORCID: http://orcid.org/0000-0001-6630-796X \\ nathaliacosmo@ufv.br
}

\section{RESUMO}

Este estudo analisa os conflitos relacionados à posse, uso, gestão e criação do território protegido, atualmente denominado de Reserva Extrativista Extremo Norte do Tocantins. A análise é feita a partir do conflito enquanto elemento constituinte da memória do território que conforma a Unidade de Conservação (UC). Para este estudo qualitativo foram combinadas revisão bibliográfica, com dados secundários (fontes oficiais) e dados primários (notas de campo). Como resultado, se identificou a falta de coordenação entre os objetivos das políticas públicas agrícolas, energéticas, ambientais e de integração do território na região de abrangência da Resex. Tal falta de articulação é, inclusive, alavanca para tensões entres os diversos atores que compartilham esta realidade. A tensão entre os agentes sociais está relacionada à tomada de decisão derivada de diferentes lógicas de apropriação de recursos naturais. Os agentes sociais da Reserva Extrativista mantêm relações tradicionais estabelecidas entre sociedade e natureza através da exploração do coco babaçu (Attalea speciosa). Além disso, novos atores sociais ocupam extensos espaços de áreas nesse território, 
a exemplo disso se tem a criação de gado, a qual onera efeitos à exploração do babaçu e aos objetivos da UC, dentre estes: a privatização dos recursos vegetais e; a transformação abrupta da paisagem e consequentemente a diminuição do recurso natural em questão. O ponto chave para entender o conflito é a regularização fundiária, uma vez que a área da UC é sobreposta em propriedades privadas que ainda estão pendentes de regularização, levando a tensões e processos de exclusão e de servilismo aos usuários da UC por parte dos fazendeiros.

Palavras Chave: Unidade de Conservação, Reserva Extrativista, Recursos Naturais.

\section{Abstract}

This study analyzes the conflicts related to the possession, use, management and creation of the protected territory, nowadays called Extractive Reserve Extremo Norte do Tocantins. The analysis is made from the conflict as a constituent element of the memory of the territory that conforms the federal protected areas (PAs). For this qualitative study, bibliographic reviews were combined, with secondary data (official sources) and primary data (field notes). As a result, was identified a lack of coordination between the objectives of the agricultural, energy, environmental and territorial integration policies in the region covered by the Resex , such a lack of articulation is also a lever for tensions between the various actors that share this reality. The tension between the social agents is related to the decision making derived from different logics of appropriation of natural resources. The social agents of the extractive reserve maintain traditional relations established between society and nature through the exploitation of babassu coconut (Attalea speciosa). In addition, new social actors occupy large areas in this territory, for example cattle raising, which has effects on the exploitation of babassu and PAs objectives, among them: the privatization of plant resources and the abrupt transformation of the landscape and, consequently, the reduction of the natural resource in question. The key point to understand the conflict is the land regularization, since the area of the PAs is superimposed on private properties that are still pending of regularization, leading to the tensions and processes of exclusion and servility to the users of the PAs by the farmers.

Keywords: Federal Protected Areas, Extractive Reserve, Natural Resources.

\section{INTRODUÇÃO}

Os espaços naturais protegidos no Brasil apresentam configuração própria para cada categoria de conservação e uso do território e dos recursos naturais. Sua criação, implantação e gestão estão previstas na Lei 9.985 de 18 de julho de 2000, que institui o Sistema Nacional de Unidades de Conservação da Natureza (SNUC). Nessa normativa, estão descritos os critérios de uso e gestão de dois grandes grupos de Unidades de Conservação (UC), as de Uso Sustentável e as de Proteção Integral.

Dentro do grupo das UCs de Uso Sustentável, que têm como objetivo "garantir o direito de comunidades tradicionais ao uso dos recursos naturais renováveis de forma socialmente justa e economicamente viável a fim de garantir sua perenidade" (Teixeira et al., 2017, p.72), encontra-se descrita a categoria Reserva Extrativista (Resex). O surgimento dessa categoria é fruto da luta dos sindicalistas e seringueiros da Amazônia nos anos 1980. 
Os seringueiros defendiam a conservação da floresta e de seus recursos como forma de resistência ao modelo excludente de desenvolvimento econômico da época, que desconsiderava as populações tradicionais e seus modos de vida (Cunha, 2010). De fato, a referida década foi marcada, em todo Brasil, pelo florescer de diversos movimentos sociais relacionados à luta pela posse e uso da terra. Os demandantes eram camponeses sem terra ou com pouca terra, indígenas, quilombolas, e outras populações tradicionais. Muitos destes atores sociais tiveram suas terras originais expropriadas em razão do processo de avanço da fronteira agrícola em direção ao interior do país, especialmente na Amazônia (Minc, 1985).

Já na década de 1990, as mobilizações por parte das populações extrativistas de seringa da região Norte se intensificaram com o objetivo de impulsionar a criação das Reservas Extrativistas (Resex). Esse movimento teve Chico Mendes ${ }^{1}$ como seu principal representante, cuja morte deu visibilidade e repercussão nacional e internacional à luta dessas comunidades, demonstrando que seus modos de vida e trabalho dependiam dos recursos naturais, os quais eram protegidos pelas mesmas e utilizados de forma sustentável (Cunha, 2001).

Nesse contexto, a criação de UCs de Uso Sustentável foi estimulada no Brasil, como destacam Rolla, Ribeiro e Vedoveto (2011), principalmente a partir de 1990, por três motivos principais: a) as UCs dessa modalidade permitiam o uso econômico dos recursos naturais, tornando sua criação e implementação politicamente mais aceitável que uma UC na modalidade de proteção integral; b) a própria pressão exercida pelos movimentos sociais da época, apoiados por organizações não governamentais e organizações nacionais e internacionais em defesa do meio ambiente e das populações locais, sejam as ribeirinhas, extrativistas, etc., questão que fortaleceu, também, a pauta das Resex e; c) a criação de Florestas Nacionais e Estaduais foi fomentada pelo Estado, como forma de viabilizar a exploração madeireira ordenada e em áreas regularizadas do ponto de vista fundiário.

Entretanto, apesar de todo o aparato legal instituído pelo SNUC e demais legislações ambientais, associado à criação de órgãos específicos para propor, implantar, gerir, proteger, fiscalizar e monitorar as UCs, como o Instituto Chico Mendes de Conservação da Biodiversidade - ICMBio (criado em 2007, vinculado ao Ministério do Meio Ambiente - MMA) e suas ramificações, a consolidação das UCs de Uso Sustentável no Brasil ainda é um desafio. Sendo um dos principais entraves à implantação e concretização de UCs dessa natureza sua consolidação territorial (Futada, 2011).

Para Futada (2011), a ausência de regularização fundiária nas UCs federais decorre de questões como a lentidão administrativa e carência orçamentária, porém, está associada também à inexistência de um cadastro fundiário oficial, integrado e atualizado, a nível federal, estadual e municipal. Nesse contexto, é atualmente, inviável identificar detalha-

1 Chico Mendes foi um seringueiro, sindicalista, ativista político e ambientalista brasileiro. Lutou a favor dos seringueiros da Bacia Amazônica, cuja subsistência dependia da preservação da floresta e das seringueiras nativas (Allegretti, 2008). 
damente a situação fundiária de cada UC no país. Apesar dessa desinformação, a realidade que se apresenta é de um "conflito generalizado" no que trata da questão fundiária nessas áreas protegidas, como destaca a autora. Para exemplificar a gravidade da situação, segundo dados do ICMBio, até 2011, três em cada 10 hectares em UCs federais eram terras particulares. Das 215 UCs federais existentes nessa data, as quais, obrigatoriamente, deveriam ter seu território de domínio público, 188 ainda possuíam terras particulares em seu interior (ibidem).

Essa é a realidade da Reserva Extrativista do Extremo Norte do Tocantins, a qual, passados mais de 25 anos de sua criação, permanece enquanto área privada, sob domínio de fazendeiros, que impedem o acesso aos recursos naturais de seu território por parte das populações extrativistas, que são suas beneficiárias por direito. A ausência de regularização fundiária da área da Resex é fator causador de conflitos entre esses agentes, como destacam Vieira e Sousa (2017). Esses conflitos opõem lógicas distintas de uso e vivência do território, caracterizadas por uma parte (fazendeiros) pela propriedade privada e por outra (extrativistas) pelo senso comunitário, de pertencimento ao meio e de dependência dos recursos.

Para melhor entender a questão dos conflitos sociais que se apresentam em torno da legitimação das Resex no contexto de luta por direitos das populações tradicionais e extrativistas, no presente artigo serão discutidos elementos relacionados aos conflitos sociais vivenciados pela população beneficiária da Resex Extremo Norte do Estado do Tocantins, ora denominada por REENT. A Resex em questão está localizada na região denominada Bico do Papagaio, no Norte do Brasil, região marcada por intensos conflitos fundiários. Para a análise desenvolvida, considera-se que o conflito é elemento constituinte da memória do território que atualmente se (re)configura enquanto UC. Neste sentido, é conexo o argumento de Pool e Loughlin (2017) de que a memória social deve ser entendida como uma entidade em constante evolução, que pode ser modelada e mudada por interesses concorrentes em um processo contínuo de conflito e negociação.

\section{PROCEDIMENTOS METODOLÓGICOS}

O presente estudo trata-se de um trabalho de natureza qualitativa, pois os conflitos e tensões relacionadas à posse e o uso de territórios constituem fenômenos sociais fundamentalmente complexos que envolvem a desigual distribuição de poder na sociedade e a luta por reconhecimento social e por direitos de uso e posse da terra que historicamente foram negligenciados a grupos marginalizados, como as comunidades tradicionais. Todas essas questões demandam uma análise em profundidade, a qual pode ser garantida pela abordagem qualitativa que, segundo Paton (1990), objetiva construir um marco para comunicar a essência do que os dados revelam. De acordo com Godoy (1995), as pesquisas qualitativas têm em comum as seguintes características: 1) a valorização do contato direto do pesquisador com o ambiente/situação estudada; 2) a natureza descritiva, uma vez que 
os dados coletados na pesquisa de campo nos formatos de transcrições de entrevistas, anotações de campo, fotografias, videoteipes, desenhos e vários tipos de documentos exigem uma análise robusta (descritiva) a fim de entender o fenômeno social em questão; 3) o esforço em compreender estes fenômenos pela perspectiva dos participantes; 4) utilização do enfoque indutivo, uma vez que os pesquisadores não estão presos a hipóteses predeterminadas, mas partem de perguntas amplas que vão se redesenhando no decorrer da pesquisa.

A questão ampla orientadora dessa pesquisa é: $\mathrm{O}$ conflito como elemento constitutivo da memória de um território em disputa traz à tona não só as assimetrias de poder entre os atores sociais envolvidos, mas refletem as disputas sociais, econômicas, políticas e culturais em torno diferentes concepções sobre como deve se desenvolver as relações entre natureza e sociedade.

O conflito como um fenômeno essencialmente complexo exige métodos e formas de observação capazes de lidar com a sua natureza. Assim, a fim de resgatar a memória do território, foi construída uma linha do tempo a fim de recuperar, via diferentes fontes, os eventos e lógicas que conformaram o conflito. A técnica de construção da linha do tempo é primordialmente defendida por Prigogine (1997), um dos precursores da transformação da relação da ciência com o tempo. Para o autor, a linha do tempo apresenta a possibilidade de interpretar a história dos sistemas e a irreversibilidade das transformações como forma de explicar seu estado atual pela sua distância do equilíbrio. Para Maldonado (2009), o passado se configura como um sistema aberto à medida que pode ser reescrito, reinterpretado e ressignificado. A complexidade aumenta à medida que o movimento do presente aprofunda o passado, em conformidade com a própria evolução do pensamento e da cultura. A complexidade é então uma característica introduzida por quem observa o tempo histórico. Deste modo, a reconstrução histórico-sociológica do conflito envolvendo a constituição da REENT, poderá contribuir com um eventual enfrentamento do problema considerando sua complexidade.

Quanto aos instrumentos, os dados primários foram coletados via anotações de campo, em 2014, durante um trabalho de levantamento das famílias beneficiárias da referida Resex. Tanto a coleta de dados secundários, fontes oficiais, teses, dissertações, artigos científicos, entre outros, como a revisão bibliográfica, foram paralelamente realizadas até 2018, a fim de conferir maior robustez e validade à análise.

\section{RESULTADOS E DISCUSSÃO}

\subsection{Conflito sociais e fundiários no Bico do Papagaio: memória do território}

O estado do Tocantins foi constituído em 1988, sendo que, até a referida data, esse território formava parte do estado de Goiás. Como destaca Chaves $(2015$; 2017), a constituição do mais novo estado brasileiro foi um ponto de inflexão na intensificação de conflitos por terra na região. Associado a esse fato, outros processos se desenvolviam na mesma, como a expansão da fronteira agrícola para a Amazônia e a abertura de novas 
frentes de ocupação pela implantação de rodovias, como a BR-230, também conhecida como Rodovia Transamazônica (Oliveira; Sousa, 2016).

O Bico do Papagaio, especificamente, tem sua dinâmica de ocupação territorial ligada à presença de indígenas e quilombolas, além dos migrantes das frentes de expansão mais antiga, formada por trabalhadores dos estados do Nordeste, como Maranhão, Ceará e Piauí. Esses buscavam terras desocupadas para a prática da agricultura e do extrativismo, consolidando a dinâmica de produção de subsistência que caracteriza a região (Sousa; Silva, 2017; Vieira, 2018).

A área na qual se localiza a REENT está inserida na abrangência do território do Bico do Papagaio (Figura 1), onde, de acordo com Rocha (2011) e Vieira (2018), se manifestam dinâmicas socioambientais diferenciadas, como a do extrativismo do babaçu, além de se encontrar na área de expansão da fronteira agrícola brasileira, em direção à Amazônia. Por essa razão, a área de estudo foi alvo de fortes investimentos, políticas de incentivos produtivos e fiscais, principalmente a partir das décadas de 1960 e 1970, período da ditadura militar no Brasil, além da ação de grileiros ${ }^{2}$, que se apropriaram de vastas extensões de terra na região.

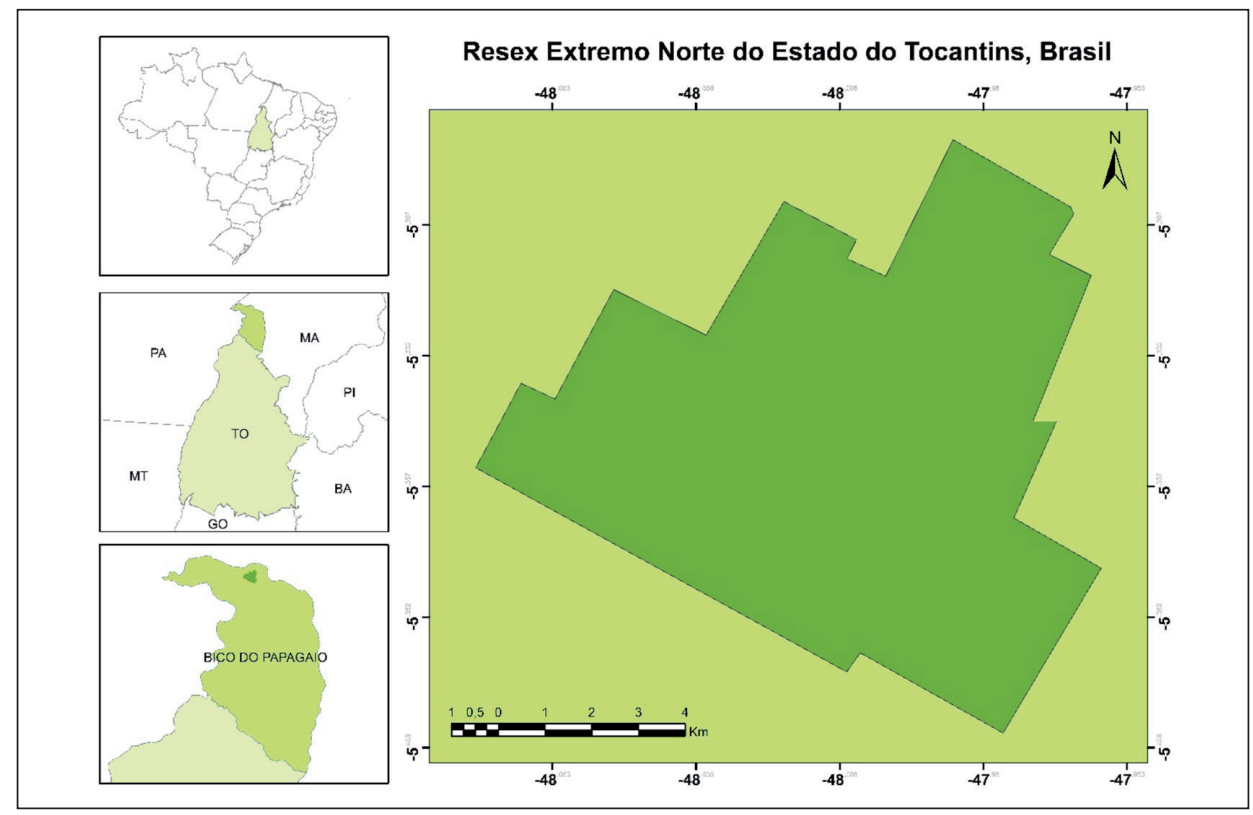

Figura 1. Localização da Resex Extremo Norte do Estado do Tocantins, TO - Brasil.

Fonte: Elaborado pelos autores com base em IBGE (2018), Sistema de Coordenadas Geográficas - Datum: SIRGAS, 2000.

2 De acordo com Gehlen (1994) o termo grileiro é utilizado para designar a apropriação privada de terras através da força, da chantagem, da falsificação de documentos ou por influência pessoal junto a órgãos responsáveis. No processo de falsificação dos documentos, os falsos papéis eram guardados numa gaveta com grilos por alguns dias, para obter o aspecto de antigo e amarelado, mais próximo dos originais. 
A dinâmica econômica e social que se instaurou no território do Bico do Papagaio, a partir desses processos, gerou graves conflitos entre os proprietários de terra (fazendeiros, grileiros) e as populações tradicionais e camponesas que viviam da coleta do coco babaçu e da agricultura de subsistência. Tais famílias de lavradores pobres dependiam diretamente da agricultura de subsistência e do extrativismo, assim, as áreas onde trabalhavam se configuravam como local de viver, de plantar e de coletar. O aumento no número de fazendas e o estabelecimento dos rebanhos de gado na região privava os meios tradicionais de vida das famílias ali estabelecidas (Chaves, 2015; Sousa; Silva, 2017; Vieira, 2018), agravando a situação de tensão e intensificando os conflitos na região.

Sob a perspectiva de Chaves (2015), e com base em argumentos discutidos por Vieira (2018) e Vieira e Souza (2017), o conflito social na região do Bico do Papagaio é resultado dessas políticas de ocupação capitalista e da concentração dos recursos (terra e capital) nas mãos dos mais poderosos (fazendeiros). Essa realidade configura um conflito histórico de luta pela terra e pelos recursos do território, onde seus atores (fazendeiros, latifundiários e populações camponesas e extrativistas) possuem lógicas distintas de apropriação dos recursos naturais. São contrastados, nessa perspectiva, a propriedade privada, representada pelos fazendeiros, e o uso e a vivência das comunidades extrativistas e tradicionais, que se organizam a partir de um senso comunitário e de envolvimento socioambiental, como discutido por Vieira e Souza (2017).

A consolidação desse território como região de conflitos ocorreu, a princípio, no período da ditadura militar, frente ao intenso processo de luta pela terra por parte de camponeses, quilombolas e indígenas, como afirma Chaves (2015; 2017). Segundo essa autora, a partir de 1992, período do governo dos presidentes do Brasil Collor/Itamar, houve uma diminuição nos conflitos. No entanto, a partir de 1996 são registrados novos picos de conflitos, principalmente em 1996, e nos anos seguintes do governo Fernando Henrique Cardoso, que durou até 2003. A partir de então, se iniciou um decréscimo, com um gradativo aumento no número de conflitos no Brasil, e também na região do Bico do Papagaio, a qual permanece, até 2014, como a região com maior número de conflitos no campo no país, como destacam Rocha (2011) e Chaves (2015; 2017). A Figura 2 apresenta um resumo da configuração temporal dos conflitos na região.

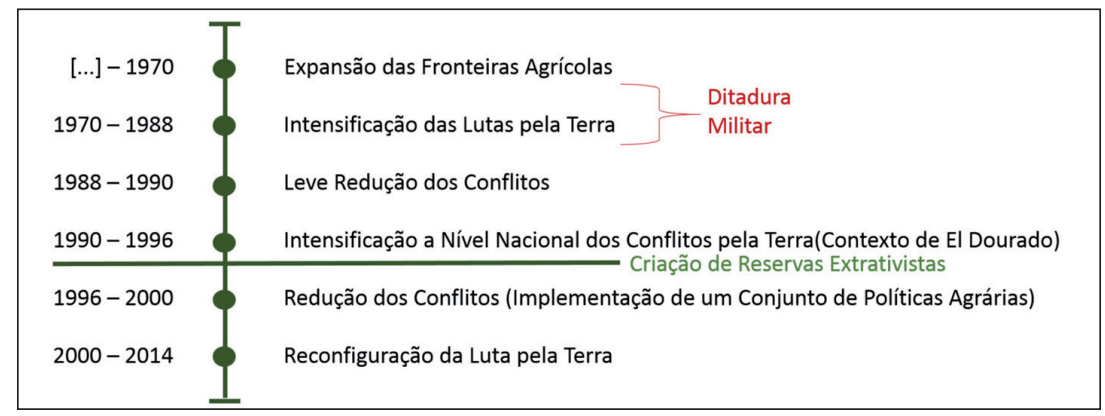

Figura 2. Linha do tempo dos conflitos na região do Bico do Papagaio.

Fonte: Elaborado pelos autores com base em Chaves (2015; 2017), 2018. 
Frente aos conflitos com os grandes latifundiários, fazendeiros, ou mesmo empresas, as populações camponesas da região organizados em movimentos sociais ou grupos de pressão, trazendo elementos de identificação como marcas de suas reivindicações (quilombolas, indígenas, quebradeiras de coco babaçu, etc.), construíram estratégias específicas de conquista ou permanência na terra e de direito sobre o território e seus recursos (Chaves, 2015; 2017), como os assentamentos rurais e as Reservas Extrativistas, processo que será discutido na seção a seguir.

\title{
2.2. Criação da Resex Estremo Norte do Estado do Tocantins e a patologia do processo de desenvolvimento
}

A proposta em torno das Reservas Extrativistas tangencia a criação de áreas de domínio público, as quais seriam utilizadas de forma coletiva, garantindo às comunidades tradicionais o uso dos recursos naturais do território, com regras de uso e gestão definidas pelo poder público (Allegretti, 2008). Entretanto, seu reconhecimento, enquanto categoria de manejo, equivalente às demais UCs, só ocorre com sua inserção no SNUC no ano 2000. A partir desse reconhecimento, institui-se que:

\begin{abstract}
A Reserva Extrativista é uma área utilizada por populações extrativistas tradicionais, cuja subsistência baseia-se no extrativismo e, complementarmente, na agricultura de subsistência e na criação de animais de pequeno porte, e tem como objetivos básicos proteger os meios de vida e a cultura dessas populações, e assegurar o uso sustentável dos recursos naturais da unidade (SNUC, 2000, p.27).
\end{abstract}

Seu domínio é público e o uso cedido às populações extrativistas tradicionais que residem em seu interior e entorno. Está prevista, para sua efetivação, a desapropriação das áreas particulares incluídas em seus limites, conforme legislação específica.

Para além do elemento ambiental, o tratamento legal conferido pelo SNUC à categoria Resex, e outras categorias de UCs de Uso Sustentável, aborda aspectos relacionados às questões sociais, econômicas e culturais das populações tradicionais. Nesse sentido, as Resex no Brasil representam mais que um instrumento de preservação ambiental. Elas se legitimam como um instrumento de garantia do direito de uso do território para as populações que nelas residem, respeitando as especificidades de seus modos de vida (Cunha, 2001). No entanto, esta legitimação não é um processo livre de conflitos e tensões entre os atores sociais envolvidos, que até os dias atuais disputam a posse e o uso de tais territórios, seja na esfera pública, na figura do Estado, seja na privada, nas lutas pelo direito sobre terras griladas ou apropriadas de forma particular, por exemplo.

Nesse sentido, sobre o contexto de mobilização social pelo reconhecimento dos direitos das famílias extrativistas de babaçu sobre o território na região do Bico do Papagaio, Sousa (2015) destacou como importante evento a desapropriação de uma área no município de São Miguel (TO), em 1986, com o objetivo de criar um assentamento rural 
da reforma agrária, denominado Sete Barracas. Entretanto, nem todas as famílias participantes da mobilização foram beneficiadas por esse projeto de assentamento, motivando novas ações. Foi fundamental nesse processo, como discutem Oliveira e Sousa (2016), Silva (2011) e Vieira (2018), a atuação dos Sindicatos dos Trabalhadores Rurais (STRs) e da Comissão Pastoral da Terra (CPT), que mobilizaram e organizaram os trabalhadores rurais e extrativistas da região. Essa mobilização buscava uma "justiça social", que seria caracterizada pelo direito de uso do território (Vieira e Souza, 2017).

Nesse ambiente de ameaças às comunidades tradicionais e de forte mobilização das populações locais, apoiadas na trajetória de luta pela terra na região, se fortaleceram a mobilização para a criação de uma Reserva Extrativista, próxima ao assentamento Sete Barracas. Nesse contexto, no ano de 1992 foram criadas três Resex na região do Bico do Papagaio: Resex Ciriaco (MA), Resex Mata Grande (MA) e Resex Extremo Norte do Estado do Tocantins (TO) (Oliveira; Sousa, 2016). Sousa (2015) ressalta, assim, que a criação dessas áreas protegidas ocorreu, não casualmente, catorze dias antes do início da ECO92 (I Conferência das Nações Unidas sobre o Meio Ambiente e Desenvolvimento), no Rio de Janeiro. Segundo Yohannes (2013) havia pressa na criação da Resex Extremo Norte, em função da ECO92 que fazia ecoar a demanda internacional por uma efetiva política ambiental no Brasil. Dessa forma, ainda que a sua criação fosse motivada por interesses sociais e para fins ecológicos (BRASIL, 1992), essa foi desacompanhada de um real entendimento das comunidades locais sobre o verdadeiro significado do que viria a ser uma Reserva Extrativista, com seus objetivos sociais e ambientais. E das diferenças entre essa e um assentamento rural, que atende os objetivos de acesso à terra, nos moldes da reforma agrária no Brasil (Oliveira; Sousa, 2016).

No que tange aos entraves à consolidação da REENT, Castilho (2009) e Oliveira e Sousa (2016) relatam que em 1993 houve uma série de mobilizações por parte de grupos contrários à Resex, visando sua extinção. Os argumentos apresentados às autoridades (Ministério Público Federal) por esses grupos incluíam: 1) utilização inadequada do solo por parte das comunidades, em razão do desflorestamento das áreas onde coletavam o babaçu; 2) aumento dos conflitos entre população tradicional e fazendeiros com a criação da Resex; 3) inexistência de organizações formais e informais dos extrativista. Num segundo momento, tal como relata Sousa (2015), os fazendeiros impediram que as organizações governamentais (IBAMA - Instituto Brasileiro do Meio Ambiente e dos Recursos Naturais Renováveis; CNPT - Centro Nacional de Desenvolvimento Sustentado das Populações Tradicionais) fizessem a avaliação da área demarcada para a Resex para garantir a regularização fundiária. Finalmente, pouco antes da finalização do processo que visava a regularização fundiária da área, os fazendeiros expulsaram os moradores dos povoados que existiam em seu interior, extinguindo os mesmos (Castillo, 2009; Oliveira; Sousa, 2016).

Em 1994, diante da avaliação in loco da REENT, bem como da Resex Mata Grande, pelo IBAMA, na época órgão responsável pela criação e gestão das UCs no Brasil, e pelo INCRA (Instituto Nacional de Colonização e Reforma Agrária), responsável pelas questões fundiárias, representantes da sociedade civil, como Sindicatos de Trabalhadores 
Rurais e grupos locais, foi constatado que as condições ambientais e sociais em que se encontravam sua zona de abrangência não justificavam a consolidação das referidas UCs, como afirma Castillo (2009). Sendo o ano de 1994 o limite para a desapropriação das fazendas na área e consolidação da mesma enquanto Resex e essa não ocorrendo, invalidou os decretos de criação (Dias, 2005). Em 1996, o Ministério do Meio Ambiente (MMA), apoiado nos resultados das avaliações realizadas em 1994, encaminhou uma recomendação formal por meio de projeto de lei (PL n².598/1996), para proceder a extinção da Reserva Extrativista Extremo Norte do Estado do Tocantins e Mata Grande (Castilho, 2009).

Esse projeto de lei, segundo Sousa (2015), chegou, tardiamente, em 1999, ao conhecimento da população local, que, por sua vez, se mobilizou por meio de cartas, ofícios e monções às autoridades do governo federal, com o objetivo de reverter o processo de revogação da REENT, e demais UCs da região que se encontravam em situação similar. A falta de clareza sobre os objetivos e funcionamento da Resex, argumenta a autora, impedia o processo de fortalecimento social para a defesa do território. Entretanto, apesar de debilitadas pela falta de informação e assimetrias nas relações de poder, as ações pelo reconhecimento social do território dos extrativistas e pequenos agricultores caminharam para o plano formal, e se consolidaram institucionalmente.

Essa nova fase da organização dos extrativistas e demais populações tradicionais da região é marcada pela criação, no dia 25 de abril de 1999, do Sindicato dos Trabalhadores e das Trabalhadoras Rurais de Carrasco Bonito (STTR-CB), primeira instituição formal criada em defesa do território e de seu uso por parte das populações tradicionais locais. Em 2001, foi criada a Associação da Reserva Extrativista do Extremo Norte do Tocantins (ARENT), para garantir a representação e organização das extrativistas da REENT (Sousa, 2015; Oliveira; Sousa, 2016).

Segundo Sousa (2015), como resultado desse novo processo de mobilização e organização das comunidades locais, em 2002, se iniciou o cadastro e levantamento socioeconômico das famílias tradicionais residentes na área de abrangência dessas Resex e um estudo para apoiar o processo de desapropriação das fazendas localizadas em seu interior. Outra possibilidade de desapropriação dos fazendeiros na região se deu por meio do Plano de Aproveitamento Hidroagrícola Sampaio, localizado no município de Sampaio (TO). Esse projeto destinava 1.070 hectares de área irrigada aos fazendeiros, para a produção de grãos e frutas. A obra seria inteiramente financiada pelo governo do estado do Tocantins. No entanto, uma parte de sua área encontrava-se sobreposta à área da Resex, o que desencadeou outra onda de mobilizações por parte dos movimentos populares da região. Esses argumentavam que o Projeto Sampaio era uma ameaça ao desenvolvimento socioterritorial da região e teve como resultado o impedimento parcial de sua implantação, evitando da sobreposição entre os dois projetos de uso da terra (Sousa; Silva, 2017).

Diante desses entraves, ocorre então, em 2006, a terceira tentativa de regularização fundiária da área da REENT por parte do Estado. Na ocasião foram identificados 58 proprietários rurais, quando no primeiro levantamento, em 2001, haviam sido levantados apenas 12. Ao não ter segurança sobre os dados reais a respeito da propriedade da terra 
no interior da Resex, outra vez as ações de regularização fundiária não se concretizaram (Sousa, 2015). Assim, como argumentam Vieira e Souza (2017), a área da Resex configura-se, ainda nos dias atuais, como um território em litígio.

A situação de insegurança no que trata da questão fundiária na REENT, perpetua o conflito entre fazendeiros e extrativistas, conflitos que, como já citado, opõem a propriedade privada ao uso e à vivência na Resex, a partir de um senso comunitário (Vieira, 2018). Essa realidade é evidenciada, por exemplo, nas narrativas presentes na investigação de Sousa (2015), que evocam o acontecimento localmente denominado como capetagem. Essa consistia na entrada dos fazendeiros e seus empregados nas terras onde se realizava o extrativismo e sua cobertura com um composto químico formado por óxido ou hidróxido de cálcio, chamado popularmente de cal, como forma de inviabilizar a coleta do babaçu.

Nesse contexto, a chave para o entendimento dessa intensificação no conflito entre fazendeiros e populações extrativistas, está no fato da criação da Resex não ter sido acompanhada da concessão do direito de uso do território e dos recursos naturais às comunidades tradicionais, nem pela restrição da produção pecuária na área, ambas dependentes da regularização fundiária dessa. A influência política dos fazendeiros, associada à falta de planejamento na criação da Resex por parte do Estado, são apontadas como razões para a desapropriação, prevista pelo Decreto no 535/1992 que institui a REENT, nunca ter ocorrido (Sousa, 2015).

A insegurança e o medo a respeito das implicações da criação da REENT, fez com que os fazendeiros, donos ou possuidores do título de propriedade, hostilizassem, ainda mais, a atuação das quebradeiras de coco babaçu em suas áreas. Nesse contexto, as atividades de coleta e quebra do babaçu, antes realizada dentro das fazendas é, em muitas comunidades, proibida ou seriamente restringida. Dentre as restrições feitas pelos fazendeiros, está a proibição da queima da casca do babaçu para produção de carvão próxima às pastagens, uma vez que essa prática poderia causar incêndios e destruir as mesmas, prejudicando a atividade pecuária.

Essa "nova configuração" do trabalho, ou seja, a necessidade de transporte do coco inteiro, é relatado pelas quebradeiras como um dos principais problemas no desenvolvimento da atividade extrativista do babaçu (Dados da pesquisa, UFV, 2014). Tais restrições não só dificultam a otimização do trabalho, como representa um não reconhecimento do direito conferido à classe extrativista. Em outras palavras, os fazendeiros exercem o papel de limitadores do uso em um território que foi por lei reconhecido como de direito da população extrativista. Nesse sentido, além do acesso aos recursos naturais (coco babaçu), a questão fundiária ainda se apresenta como elemento chave de conflito na região. A não desapropriação da área onde se criou a REENT, manteve a situação de vulnerabilidade das comunidades locais que dependem do extrativismo e da agricultura como meio de subsistência.

O não direito de uso da terra e do território mantém a situação de dominação dos fazendeiros sobre as populações locais, seja pela dependência de autorização para coleta do coco, ou pela proibição de fazê-lo nas áreas das fazendas, seja pelo sistema empregado 
no cultivo agrícola, no qual aqueles que não têm nenhuma terra dependem do sistema de meia, terça, ou quarta, para produzir (principalmente feijão, milho, arroz e mandioca). Esse sistema de cultivo é muito utilizado, nas regiões com grande número de agricultores com pouca terra. Consiste no plantio de culturas anuais nas áreas de terceiros, os quais recebem, no momento da colheita, uma porcentagem da produção $(50 \%$, no caso da meia; um terço, no sistema chamado terça; e $25 \%$ para a quarta). Tal sistema apresenta muita similaridade com o princípio econ hist do feudalismo que se assentava na submissão de vassalo ao suserano.

Foi identificado por meio de entrevistas e observação participante, que por parte dos moradores das comunidades locais, principalmente aquelas que dependem do extrativismo, há o imaginário do acesso à terra por meio da consolidação da REENT. São muitos os relatos que evocam que, com a desapropriação da área da Resex, as famílias serão transferidas para o interior da mesma, onde serão construídas novas casas e esses passarão a residir e trabalhar. Esse imaginário está ligado ao processo ocorrido na Resex Ciriaco, onde as famílias conquistaram o direito e os meios para residir no interior da UC, fato que não ocorreu após a criação da Resex Extremo Norte do Tocantins.

Percebe-se, assim, por meio das narrativas, pouco conhecimento dos objetivos reais da criação e consolidação das Resex, que teriam foco no uso sustentável dos recursos naturais. Na verdade, os atores sociais tem expectativas que a criação da Resex lhes confira os mesmos direitos que a criação de assentamentos de reforma agrária. Nesse contexto, grande parte dos moradores locais estão mais interessados no acesso à terra que no desenvolvimento do extrativismo. Essa realidade se justifica pela marcante presença da agricultura de subsistência entre essas populações. Entre as famílias entrevistadas pelo ICMBio e UFV, no ano de 2014, por exemplo, 46,5\% declaram desenvolver a agricultura, principalmente o cultivo de milho, feijão, arroz e mandioca, sendo uma das principais dificuldades relatadas a falta de terra para plantar $(15,3 \%)$, a qual seria suprida com a consolidação da Resex, segundo o imaginário desses. Assim, segundo Sousa (2015) não ficou claro para a população local que a Resex se propõe a preservar as relações ancestrais entre os indivíduos e a natureza, de forma distinta ao assentamento rural tradicional que, por sua vez, apoia principalmente o acesso à terra e o desenvolvimento de atividades agrícolas.

Além disso, grande parte dos relatos dos extrativistas e dos trabalhos que estudaram a realidade da REENT aqui citados evidenciam que sua criação acabou por ampliar a restrição do uso do coco babaçu por parte dos fazendeiros. Isso porque sua criação não foi acompanhada por processo efetivos de consolidação dos direitos dos extrativistas sobre o território e os recursos, o qual deveria ter ocorrido, inicialmente, com a regularização fundiária.

\subsection{Assimetria de Poder, Regularização Fundiária e a Ação do Estado: a manutenção das privações substantivas e dos conflitos na REENT}

A realidade apresentada na seção anterior, relacionada à inseguridade em relação a informação dos territórios, é uma problemática recorrente da questão agrária brasileira, e 
gera consequências nas diferentes formas de uso, ocupação e nas estratégias de sucessão das populações nos espaços rurais. Dessa forma, essa problemática é entendida como uma barreira para a gestão e articulação de ações e políticas públicas que buscam melhores condições de apropriação e convivência com os recursos naturais e de vida para populações rurais e tradicionais que têm lutado por direitos sobre estes territórios. No caso dos espaços de uso coletivo, como as Resex, a regularização fundiária assume um papel ainda mais importante, por ser uma das formas de legitimação do direito sob o território por parte desses sujeitos (Menezes, 2015; Araújo et al, 2008). É justamente essa vertente da ação fundiária que configura uma das principais demandas da REENT, sendo sua ausência uma forma de manutenção das relações assimétricas de poder.

De forma geral, a ação fundiária é formada por duas vertentes: a redistribuição e reorganização do território, que consistem em se fazer uma identificação e incorporação de terras devolutas ou destinadas à reforma agrária ao patrimônio público, para que possam ser redistribuídas entre a população demandante, como, por exemplo, famílias de trabalhadores rurais sem terra. A segunda vertente da ação fundiária é a regularização em si, que tem por objetivo legalização e legitimação das posses de terras. Seu resultado é a elaboração de títulos de domínio de imóvel rural, para seus detentores individuais e o Contrato de Concessão de Direito Real de Uso (CCDRU), para terras coletivas, sob domínio da união. A exemplo dessa modalidade se tem as Unidades de Conservação de Uso Sustentável, os assentamentos rurais e as comunidades quilombolas.

De acordo com Meirelles (2001), o CCDRU é o instrumento pelo qual a administração pública transfere o uso remunerado ou gratuito de terreno público à particular, como direito real resolúvel, para que dele se utilize em fins específicos de urbanização, industrialização, edificação, cultivo ou qualquer outra exploração de interesse social.

A regularização de terras para agricultores e comunidades tradicionais representa um passo decisivo na construção da cidadania, concretizando um direito garantido pela legislação. Tal ação simboliza o reconhecimento do Poder Público e da sociedade a esse direito que já havia sido adquirido com o trabalho e a dedicação à terra. Sua importância também é justificada por ser o instrumento garantidor de direitos sob os territórios e insere os agricultores e populações tradicionais no cenário das políticas públicas sociais. Principalmente, naquelas específicas para áreas rurais, sejam elas de financiamento, de custeio ou de investimento, por meio das diversas formas de crédito rural. Como exemplo dessas políticas se tem o Programa Nacional de Fortalecimento da Agricultura Familiar (Pronaf), iniciado dos anos 1990, com o objetivo de propiciar crédito aos diferentes atores e categorias da agricultura familiar, assentados de reforma agrária, populações quilombolas, indígenas, e outras comunidades tradicionais.

Nesse contexto, reconhecer a demanda de tais agricultores e das populações tradicionais, a partir de uma perspectiva universalista, significa estabelecer critérios para a ação do Estado. Segundo Bourdieu (1996), a despersonalização dos sujeitos que demandam as ações do Estado e de suas respectivas particularidades é determinante para a universalização da mesma. Dessa forma, compreende-se que a universalização não tem o 
sentido de abrangência, mas sim de legitimação de uma classe demandante. Em termos de política de regularização fundiária, a universalização representa dar condições de equilíbrio a uma classe social historicamente desfavorecida e que permanece à margem do reconhecimento de seus direitos pelo Estado. No caso das populações extrativistas, como as da REENT, o Estado deveria agir de forma a legitimar aquilo que lhes corresponde: o direito de uso e ocupação do território.

$\mathrm{Na}$ REENT, a postura do Estado, apesar das tentativas, parece estar filiada ao interesse do conjunto de atores que detém historicamente maior poder sob o território, ou seja, os fazendeiros e latifundiários da região, favorecendo assim, a manutenção da estrutura de dominação estabelecida no território e intensificando as disputas no local. Assim, como destaca Oliveira e Sousa (2016), a inércia do Estado, associada à ausência de pressão popular, foi fator que contribuiu nas manobras desses grupos para a não efetivação da REENT.

A perspectiva do reconhecimento de demandas sociais no campo surge a partir das disputas dos sujeitos políticos em torno do controle do Estado. Como evidencia Foucault (2006), tais conflitos, além de explicitarem as contradições internas da sociedade, têm como mais expressivo resultado a legitimação da dominação e da estrutura do Estado sobre a vida privada. O ápice dessa dominação é a necessidade do Estado de reconhecer e de conceder o direito para que as famílias permaneçam no local onde vivem, produzem e se reproduzem há várias gerações.

O não reconhecimento do direito das quebradeiras de coco sobre o uso do território, nesse contexto, pode estar relacionado à assimetria de poder existente no local. Tomando como referência Bourdieu (2001) e a teoria dos campos sociais, pode-se afirmar que os conflitos que ocorrem nesse território se dão a partir da contradições e disputas entre dois grupos de agentes sociais: dos fazendeiros e latifundiários, que detém o domínio econômico sobre o território e; das famílias extrativistas que detém a legitimidade histórica de uso do mesmo. Para Bourdieu, o campo é configurado por meio de espaços sociais em rede, onde os atores selecionam entre si, dentro de dinâmicas baseadas na assimetria de poder que confere à estrutura de cada campo, às ações que irão ser tomadas e aos domínios dos diferentes tipos de capitais, gerando uma série de contradições, dentre estas, a condição de inseguridade sob o direito de uso do território. A Figura 3 apresenta um esquema da atuação do Estado frente aos campos existentes no conflito da REENT.

A partir do esquema da Figura 3 é possível observar os distintos atores que configuram campo de disputa do uso do território e dos recursos naturais nas áreas de abrangência da REENT. Nesse sentido, o Estado atua legitimando o direito do uso por parte dos trabalhadores rurais e famílias extrativistas, por meio do decreto de criação da Resex. Entretanto, dá condições, ao mesmo tempo, para a manutenção do poder e das estruturas de dominação por parte dos fazendeiros, latifundiários, empresas e grandes empreendimentos, visto a não regularização da questão fundiária e efetivação do acesso ao território por parte das populações extrativistas. 


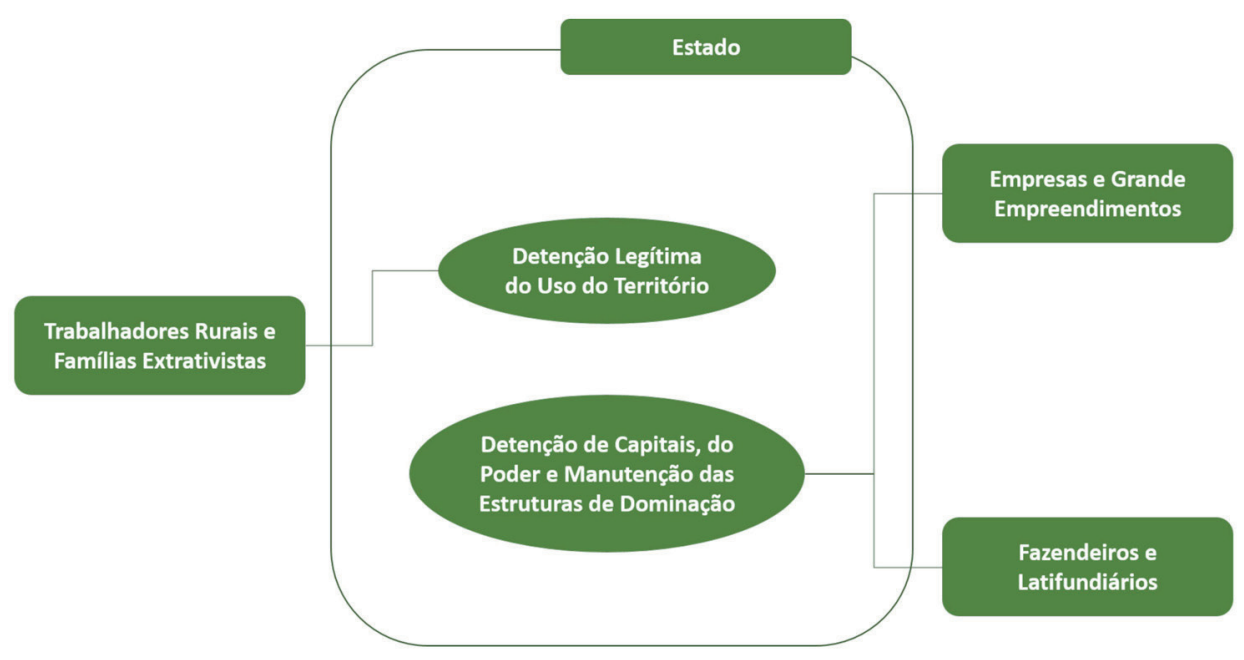

Figura 3. Campo do Conflito da Reserva Extremo Norte do Tocantins.

Fonte: Elaborado pelos autores, 2018.

Como reflexo dessas contradições, se tem uma série de privações, entendidas na literatura de Sen (2000) como liberdades substantivas. Tais privações são de ordem: a) política, representadas pelo acesso a direitos básicos, a políticas públicas e de participação; b) econômica, representada pela criação de mercados institucionais e estímulo ao acesso aos mercados formais e; c) social, representada pelo acesso aos serviços básico, como saneamento, saúde e educação. O conjunto de privações dessas liberdades geram, entre outros fatores, as condições de pobreza e limitam os processos de emancipação social.

Sendo assim, a ação fundiária, enquanto instrumento equilibrador e de justiça social, atuaria como provedora de condições que facilitam o rompimento dessas privações, por meio da ampliação das oportunidades de emancipação das populações rurais e tradicionais nos territórios. Alguns exemplos nessa direção podem ser observados na política de assentamentos rurais. A organização e distribuição dos lotes de forma individual, filiada à regularização fundiária e emissão de Declaração de Aptidão Agrícola - DAP, contribuem para o melhor desenvolvimento das assentamentos e melhores condições econômica e de reprodução social para as famílias assentadas (Duqué; Caniello, 2006), uma vez que possibilitam a essas famílias a liberdade de viver e produzir de forma digna. Liberdade que se espera alcançar, também, nas Reservas Extrativistas.

\section{CONSIDERAÇÕES FINAIS}

A privação do direito de posse do território pelas populações extrativistas da REENT, faz com que as condições de uso da terra sejam configuradas por relações hierár- 
quicas e assimétricas (produção a meia, terça, quarta e juquira - limpeza das áreas das fazendas, no sistema de diária). O acesso legal ao uso do território, além de garantir um direito legítimo, é uma ação que também iria garantir condições para o bom desempenho das atividades agrícolas e extrativistas com uma maior autonomia para as famílias beneficiárias da UC. Por outro lado, a resolução da questão fundiária na REENT atuaria na minimização de parte dos conflitos, ainda remanescentes nesse território.

A situação de conflito vivenciada pelas populações tradicionais da região determinou alterações nas relações entre natureza e sociedade, resultando em consequências como a degradação dos recursos naturais. Além disso, Sousa (2015) ressalta que as populações locais tendem a construir um modo de vida peculiar, adaptado às condições ecológicas do lugar, mas que, tendo em vista a conjuntura de diminuição das áreas de ocorrência do babaçu, estas foram, e continuam sendo, forçados a adotarem novas estratégias de reprodução social.

A partir do exposto é possível observar a falta de coordenação entre os objetivos das políticas públicas agrícolas, energéticas, ambientais e de integração do território na região de abrangência da Resex. Tal falta de articulação é, inclusive, alavanca para tensões entres os diversos atores que compartilham esta realidade.

A tensão entre os agentes sociais está relacionada à tomada de decisão derivada de diferentes lógicas de apropriação dos recursos naturais. Os agentes sociais da Reserva Extrativista mantêm relações tradicionais estabelecidas entre sociedade e natureza, por meio da exploração do coco babaçu. No outro extremo, novos atores sociais (fazendeiros), ocupam extensas áreas para produção pecuária nesse território. A criação extensiva de gado impacta a exploração do babaçu e interfere nos objetivos da UC. Dentre as consequências da configuração desse campo estão: a privatização dos recursos vegetais e da terra; a transformação abrupta da paisagem e consequentemente a diminuição do recurso natural em questão (babaçu); relações assimétricas de poder, com a exploração do trabalho dos lavradores sem terra ou com pouca terra; e a manutenção dos conflitos. Nesse campo, um dos pontos chave para entender o conflito é a regularização fundiária, uma vez que a área da UC é sobreposta a propriedades privadas que ainda estão pendentes desapropriação, levando a tensões e processos de exclusão e de servilismo junto aos usuários da REENT.

Este estudo buscou ser mais um elemento na configuração memória da Reserva Extrativista Extremo Norte do Tocantins. Tal memória é fortemente marcada pelos processos conflitivos que permearam a constituição e a resistência da Resex como área protegida. No entanto, entendendo a memória como algo dinâmico e passível de transformação, faz-se necessário realçar a urgência de políticas públicas intersetoriais, efetivas e capazes de negociar espaços de ação e compatibilizar interesses sociais com lógicas de apropriação do espaço distintas. 


\section{REFERÊNCIAS BIBLIOGRÁFICAS}

Allegretti, M.H. (2008) A construção de políticas públicas: Chico Mendes e o movimento dos seringueiros. Desenvolvimento e Meio Ambiente, Desenvolvimento e Meio Ambiente, UFPR, n. 18, p. 39-59. Doi: http://dx.doi.org/10.5380/dma.v18i0.1342.

Araujo, C. et al. (2008) Property rights and deforestation in the Brazilian Amazon. In: CERDI, Etudes et Documents, 20.

Bourdieu, P. (2001). A gênese nos conceitos de habitus e campo. In: BOURDIEU, P., $O$ poder simbólico. Rio de Janeiro. Bertrand Brasil, p. 59-74.

- (1996) Razões Práticas: sobre a teoria da ação. 6a ed. Tradução Mariza Corrêa. Campinas: Papirus.

Chaves, P. R. (2015) Rebeldia e Barbárie: conflitos socioterritoriais na região do bico do papagaio. Tese de Doutorado - São Paulo: Universidade de São Paulo.

- (2017) Rebeldia e Barbárie: Conflitos socioterritoriais na região do Bico do Papagaio. Revista Produção Acadêmica, v. 03, p. 04-24.

Cunha, C.C. (2010) Reservas Extrativistas: Institucionalização e implementação no estado brasileiro dos anos 1990. Tese (Doutorado em Psicossociologia de Comunidades e Ecologia Social). Rio de Janeiro, RJ: UFRJ.

Cunha, L. DE O. (2001) Reservas extrativistas: Uma alternativa de produção e conservação da biodiversidade. Encontro dos povos do Vale do Ribeira.

Duqué, G.; Caniello, M. (2006) Agrovila ou casa no lote: A questão da moradia nos assentamentos da reforma agrária no Cariri paraibano. Revista econômica do Nordeste, Fortaleza v. 37, n 4. Disponível em: https://www.bnb.gov.br/projwebren/Exec/ artigoRenPDF.aspx?cd_artigo_ren=383 Acesso em: 18 maio de 2018.

Foucault, M. (2006) Microfísica do poder. 22a ed. Rio de Janeiro: Edições Graal.

Futada, S. M. (2011) Avanços normativos e estruturais do SNUC na Amazônia Legal. In: Veríssimo, A. et al. (Eds.). Áreas Protegidas na Amazônia Brasileira: avanços e desafios. Belém; São Paulo: Imazom; Instituto Socioambiental.

Gehlen, I. (1994) Estrutura, dinâmica social e compreensão sobre a terra no meio rural do Sul. Cadernos de Sociologia, Porto Alegre, v.6, p.135-153.

Godoy, A.S. (1995) Introdução à pesquisa qualitativa e suas possibilidades. Revista de administração de empresas, v. 35, n. 2, p. 57-63.

Maldonado, C.E. (2009) Complejidad de los sistemas sociales: un reto para las ciencias sociales. Cinta de moebio, n. 36, p. 146-157.

Meirelles, H. L. (2001) Direito Administrativo Brasileiro. 26ed. São Paulo: Malheiros, p. 485-490.

Menezer, T. C.C. (2015) A regularização fundiária e as novas formas de expropriação rural na Amazônia. In: Estudos em Sociedade e Agricultura, Rio de Janeiro, vol. 23, n. 1 .

Minc, C. (1985) A reconquista da Terra: Estatuto da Terra, lutas no campo e reforma agrária. Rio de Janeiro: Editora Jorge Zahar. 
Oliveira, M. R.; Sousa, D. N. (2016) A luta pela regularização fundiária da Reserva Extrativista do Extremo Norte do Estado do Tocantins. Acta Geográfica, v. 10, n. 23, p. 111-129.

Patton, M. Q. (1980) Qualitative research and evaluation methods. Book Qualitative Research and Evaluation Methods.

Pool, C A.; Loughlin, Michael L. (2017) Creating memory and negotiating power in the Olmec Heartland. Journal of Archaeological Method and Theory, v. 24, n. 1, p. 229-260.

Prigogine, I; Stengers, I. (1997) The end of certainty. Simon and Schuster.

Rocha, M. R. T. (2011) A rede sociotécnica do babaçu no Bico do Papagaio-TO: dinâmicas da relação sociedade-natureza e estratégias de reprodução social agroextrativista. Tese de Doutorado - Porto Alegre: Universidade Federal do Rio Grande do Sul.

Rolla, A.; Ribeiro, M. B.; Vedoveto, M. (2011) Expansão de Unidades de Conservação de Uso Sustentável na Amazônia Legal. In: Veríssimo, A. et al. (Eds.). Áreas Protegidas na Amazônia Brasileira: avanços e desafios. Belém; São Paulo: Imazom; Instituto Socioambiental.

Silva, M. P. (2011) Padre Josimo Moraes Tavares e a atuação da Comissão Pastoral da Terra (CPT) nos conflitos agrários do Araguaia-Tocantins (1970-1986). Dissertação de Mestrado - Goiânia: Universidade Federal de Goiás.

Sousa, V. N. G.; Silva, E. (2017) As quebradeiras de coco babaçu da microrregião do Bico do Papagaio do Extremo Norte tocantinense. Revista Tocantinense de Geografia, v. 6, n. 11, p. 114-124.

Teixeira, T. H. et al. (2017) As Unidades de Conservação de Uso Sustentável no bioma Amazônico: dilemas e perspectivas para o desenvolvimento sustentável. Revista Portuguesa de Estudos Regionais, v. 45, n. 3.

Vieira, F. P. (2018) Um exercício decolonial na educação ambiental: a territorialidade em uma reserva extrativista. REMEA-Revista Eletrônica do Mestrado em Educação Ambiental, v. 35, n. 2, p. 315-332.

Yohannes, L. (2013) The evolving importance of babassu (Attaleaspeciosa) to the livelihoods of the extractivist communities of Extremo Norte Extractive Reserve, Brazil. Dissertação (MS Sustainable Development and Conservation Biology MPP Environmental Policy) - College Park, University of Maryland, Baltimore, EUA. 55p. 